\title{
COPING STRATEGIES BY STROKE CAREGIVERS: EVIDENCE FROM A QUALITATIVE STUDY IN SARAWAK, MALAYSIA
}

\author{
Md Mizanur Rahman ${ }^{1}$, Zabidah binti Putit ${ }^{1}$, Norliza binti Suut ${ }^{1}$, Mohamad Taha Arif ${ }^{1}$, Asri bin Said ${ }^{1}$, Mohd \\ Raili bin Suhaili ${ }^{2}$, Mohd Fadzillah ${ }^{3}$, Zainab binti Tambi ${ }^{1}$ and Ling How Kee ${ }^{4}$ \\ ${ }^{1}$ Faculty of Medicine and Health Sciences, Universiti Malaysia Sarawak, 94300 Kota Samarahan, Sarawak, Malaysia \\ ${ }^{2}$ Faculty of Medicine, SeGi University and Colleges, Sibu Campus, Sarawak \\ ${ }^{3}$ Faculty of Medicine and Health Sciences, Universiti Sains Islam Malaysia, Bandar Baru Nilai, 71800, Nilai, Negeri \\ Sembilan, Malaysia \\ ${ }^{4}$ Faculty of Social Sciences, Universiti Malaysia Sarawak, 94300 Kota Samarahan, Sarawak, Malaysia
}

Corresponding author: Md Mizanur Rahman

Email: rmmizanur@unimas.my; rmizanur1958@gmail.com

\begin{abstract}
Caring for stroke survivors is inevitably a burden to caregivers. It is not uncommon for stroke survivors who are discharged from the hospital and found themselves at home without any help and care from the supposed caregivers. However, in instances where there are available and willing caregivers, a sudden and unpredictable task of caring for stroke survivors require the stroke caregivers to apply their coping strategies due to the demanding nature of looking after a survivor. This study aimed to determine coping strategies undertaken by stroke caregivers in caring for stroke survivors. This was an exploratory qualitative study and data was collected from the caregivers of stroke survivor using a semi-structured guided questionnaire. A total of 18 caregivers were included in the study. The data were collected from November 2015 until June 2016 at a selected community rehabilitation centre in Kuching, Sarawak. The qualitative data analysis revealed that the coping strategies undertaken by stroke caregivers include change of role in life, self-motivation, sharing with other people, crying, trying to forget things that happen, hoping survivors will get better, emotion suppression and self-blame. The study highlighted the experiences by the caregivers for caring for stroke patients and focused on the coping strategies undertaken by the caregivers. Better ununderstanding of these experiences does help the service providers to provide better support and resources for caregivers in caring for stroke survivors.
\end{abstract}

Keywords: Stroke, caregivers, coping strategies, Sarawak

\section{INTRODUCTION}

Stroke is the third most common cause of death in developed countries, after coronary heart diseases and cancers 1. World Health Organization ${ }^{2}$ estimated that 17.7 million people died from CVDs in 2015, representing 31\% of all global deaths. Of these deaths, an estimated 7.4 million were due to coronary heart disease and 6.7 million were due to stroke. Another estimation showed that three million women and 2.5 million men died from stroke worldwide every year ${ }^{3}$. Fifteen million of the world population had a stroke with 5 million death, and another 5 million had permanent disabilities. This has contributed burdens on family and community ${ }^{4}$. Caring for a stroke survivor provides a negative impact in all aspects of a caregiver's life because of its chronic nature and long term of recovery duration. Caring for stroke survivors often give a high level of burden to the caregiver ${ }^{5}$. Hence, stroke caregivers may adopt different ways of coping strategies when dealing with the responsibility of caring for stroke survivors.

Coping can be described as the cognitive and behavioural efforts used to manage stressful situation internally or externally ${ }^{6}$. Coping strategies need the ability to screen the conditions, look for the information, think abstract and concrete as well as able to access resources and support when required ${ }^{7}$. Stroke caregivers experienced high stress which can affect their physical and psychological well-being such as developing somatic symptoms, depressive symptoms, sleep disorders and social isolation. Caregivers who have better planning and use active coping strategies can cope with the strains resulted from caring for the stroke patients ${ }^{8}$.

Stroke can cause five types of disabilities that include problems with controlling movement, sensory disturbances, including pain, difficulties in understanding language, thinking, memory and emotional disturbances 9 . Thus, stroke caregivers have to face the problems of their care recipients and coping with a disability involves cognitive and behavioural efforts in appealing the causes, meanings and the consequences of disability as well as its impact. Coping strategies include judgements and decisions, and there are two types of coping strategies which are problem-focused and emotion-focused coping ${ }^{6}$. Problem-focused coping is an effort to change or manage the sources of stress, while emotion-focused coping control the emotional responses that are caused by the situation. Problem-focused coping is related to healthy 
adjustment ${ }^{10}$ and negative emotion-focused coping such as avoidance, venting of emotions and mental disengagement will cause an increase in depression and psychological distress ${ }^{11}$. Considering this view, this was aimed to explore the experiences of caregivers managing the stroke survivors.

\section{MATERIALS AND METHODS}

\section{Study settings and characteristics}

This was an exploratory qualitative study to explore the patterns of coping strategies undertaken by caregivers of stroke survivors. The study population comprised of 18 caregivers of survivors of stroke. Healthy caregivers aged 18 years and above, staying with patients and are involved in the direct care of the patients were included in this study. The caregivers who were coming for follow up along with the patients at the rehabilitation centre who were willing to be this study participant were interviewed. Finally, six caregivers were interviewed at the rehabilitation centre, and 12 caregivers request to be interviewed at their home. The operational definition of stroke was a rapidly developing sign of focal disturbance of cerebral function lasting more than 24 hours with no apparent non-vascular cause ${ }^{12},{ }^{13}$. The caregiver was defined as "any person who, without being a professional or belonging to a social support network, usually lives with the patient and, in some way, is directly implicated in the patient's care or is directly affected by the patient's health problem"14.

\section{Data collection tools and analysis}

The semi-structured interviews were conducted using prepared questions guideline to generate dialogue in discussing the coping strategies undertaken by caregivers during caregiving. A thematic analysis was done using the procedure described by Braun and Clarke ${ }^{15}$. In the analytic process, the researchers transcribe the data first, reading and rereading the data, noting down initial ideas, followed by interesting coding features of the data into a systematic fashion, and collating data relevant to each code. After collating codes, the potential theme emerged. And thus, generating the thematic map of analysis. The ongoing analysis was done to refine and specify each theme. Finally, each theme emerged in a clear pattern demonstrating the life of the stroke caregivers.

\section{Ethical issues}

Ethical approval for this study was obtained from the Ethics Committee of Universiti Malaysia Sarawak (UNIMAS) [Ref. No\# UNIMAS/TNC(AA)-03.02/06-11 Jld.2(64)]. Voluntary participation was sought out and participants were assured about the data confidentiality. They were briefed about the aims of the study and written informed consent was obtained before the interview.

\section{RESULTS}

\section{Socio-demographic characteristics of the caregivers}

Table 1 illustrates the socio-demographic characteristics of caregivers. The mean (SD) age of the caregivers was 50.6 (14.3) years. The minimum age was 25 years and the maximum age was 73 years. Out of 18 caregivers, $94.4 \%$ were female, and the rest were male. The highest percentage had a secondary level of education (38.9\%) followed by a bachelor's degree (16.7\%). However, $16.7 \%$ had no formal education. Above $44.4 \%$ were currently employed and $38.9 \%$ were unemployed. Among them, $11.1 \%$ retired from the job. The highest percentage of the caregivers were spouse $(55.6 \%)$ followed by children (either son or daughter) comprising $22.3 \%$.

\section{Stroke caregivers undertake coping strategies}

After analysis and interpretation, eight different ways of coping strategies were found to be conducted by stroke caregivers which include change of role in life, self-motivation, sharing with other people, crying, trying to forget things that happen, hoping survivors will get better, emotion suppression and self-blame. The following sections narrated the caregiver's coping strategies accordingly.

\section{Theme 1: Problem-focused engagement}

Stroke caregivers took control over their burdens by focusing on the fundamental cause of the difficulties in caring for stroke caregivers. They made their measures to deal with the responsibilities such as changing their role in the household, and they restructure their cognitive strategies as they will be able to draw a positive perspective despite the burdens that they hold.

\section{Subtheme 1a: Change of role in life}

When the heads of the household were down with stroke and suffer from the disability, they are not able to work or send their children to the school. Thus, their spouse needs to adapt and took over these roles. For example, one wife said,

"I feel exhausted because all responsibilities are on my shoulders. Head of the family is sick and helpless". (Sarah, 43)

Another wife mentioned,

"I feel helpless because everything I need to do on my own. I am the leader of the household now. All family matters I have to do myself because my husband is sick and cannot lend his hands". (Wee, 42) 
Table 1. Socio-demographic characteristics of the caregivers

\begin{tabular}{lcc}
\hline Characteristics & Frequency & $\%$ \\
\hline Age of Caregivers (in years) & 3 & 16.7 \\
<40 & 6 & 33.3 \\
$40-49$ & 3 & 16.7 \\
$50-59$ & 4 & 22.2 \\
$60-69$ & 2 & 11.1 \\
$\geq 70$ & 1 & 5.6 \\
Caregiver's gender & 17 & 94.4 \\
$\quad$ Male & & \\
Female & 3 & 16.7 \\
Caregiver's Level of Education & 3 & 16.7 \\
No schooling & 7 & 38.9 \\
Primary school & 2 & 11.1 \\
Secondary school & 3 & 16.7 \\
Diploma & & \\
Degree & 8 & 44.4 \\
Caregiver's Employment & 7 & 38.9 \\
Employed & 2 & 11.1 \\
Unemployed & 1 & 5.6 \\
Retired & & \\
Self-employed & 10 & 55.6 \\
Relationship with the stroke patient & 3 & 16.7 \\
Wife & 3 & 16.7 \\
Daughter & 1 & 5.6 \\
Sister & 1 & 5.6 \\
Maid & & \\
Son & & \\
\hline
\end{tabular}

Table 2. The theme and subthemes emerged from the interview

\begin{tabular}{ll}
\hline Themes & Subthemes \\
\hline Problem-Focused Engagement & $\begin{array}{l}\text { Change of role in life } \\
\text { Self-motivation } \\
\text { Sharing with other people } \\
\text { Emotion-Focused Engagement }\end{array}$ \\
$\begin{array}{l}\text { Crying } \\
\text { Trying to forget things that happen } \\
\text { Hoping survivors will get better } \\
\text { Emotion suppression } \\
\text { Problem-Focused Disengagement }\end{array}$ \\
$\begin{array}{l}\text { Self-blame } \\
\text { Emotion-Focused Disengagement }\end{array}$ \\
\hline
\end{tabular}

Subtheme 1b: Self-motivation

Stroke survivors motivate themselves when they have obstacles in their life. They mentioned that they fight with their negative emotions and do not depend on fate to lead them in improving their experience. A wife noted,

"Inner self must be strong. People around us can say anything. Do not depend only on our fate to improve our lives". (Rokiah, 56)

Another wife noted, "I fight with my negative feelings". (Nisa, 48)

Problem-focused coping strategies allow stroke caregivers to develop the plan and taking control of the burden by modifying the root cause of the troubles.

\section{Theme 2: Emotion-focused engagement}

Caring for stroke survivors contribute to various burdens for caregivers. The effective coping strategies do not only involve developing the strategies to manage the load physically, but it includes caregivers' emotional reaction to the stressful pressures.

\section{Subtheme 2a: Sharing with other people}

Several stroke caregivers share their problems, feelings and opinion with their close friends and family members. Some of them also seek advice from the doctor and nurses in gathering information about caring for stroke patients. A wife said,

"I told my problem to my mother and close friends so that surrounding people understand what I have been through". (Sarah, 43)

Another wife stated, 
"I told my problem to my close friends in school. I also seek advice about caring for a stroke patient from doctor and nurse". (Rokiah, 56)

\section{Subtheme 2b: Crying}

Stroke caregiver also said that she would cry if she thinks about her fate which is not the same as other people. One wife mentioned,

"I always cry when I think about my fate that is not like other people". (Rokiah, 56)

Another wife noted, "If I feel stress, I will cry". (Wee, 42)

Emotion-focused coping strategies are effective in dealing with an unchangeable situation such as managing the burdens arising from a stroke. This coping method facilitates stroke caregivers to express their emotions and release pent-up emotions.

\section{Theme 3: Problem-focused disengagement}

Even though taking control and managing the burdens arising from caring for stroke survivors may assist the caregivers in modifying their situation, some caregivers cannot adjust with these circumstances.

\section{Subtheme 3a: Trying to forget things that happen}

Stroke caregivers reported that they always try to forget things that had already happened with the stroke survivors and the burden that they need to carry on their shoulders. A wife expressed,

"I am always trying to forget things that already happened. This problem comes very suddenly, and I am not ready. My life routine has changed 360 degrees". (Sarah, 43)

A daughter mentioned,

"I want to forget about the burden that I have. That is why I want to go for a holiday with my friends but I cannot". (Chin, 40)

Subtheme 3b: Hoping survivors will get better Stroke survivors had wishful thinking and expressed their hope that their stroke family members will recover from their illness. They want their life to be as smooth as before the stroke survivors got sick. A wife noted,

"I want our life to be as usual, and I do not want to think anymore. I hope my husband will recover from his illness". (Faridah, 56)

One respondent who is a maid mentioned, "Sometimes, I feel I want to have a quiet and easy life. When I feel stressed, I do not want to think about what had happened because it will make me worry more". (Linda, 27)
These stroke caregivers were trying to forget the situation and putting their hope that the condition will improve and get better.

\section{Theme 4: Emotion-focused disengagement}

Some of the stroke caregiver's response passively in dealing with the burden of caring demands. This was portrayed by their thoughts and behavioural adjustments.

\section{Subtheme 4a: Emotion suppression}

Several stroke caregivers keep their emotion to themselves. They talk less with other people around them. This is because, when they try to verbalise their feelings of carrying the burden from caring of the stroke survivors, the comments or feedbacks that they received from the other people are not that supporting enough for them to face the challenges. Hence, stroke caregivers prefer to keep quiet and keep a distance from people around them. A wife stated,

"When I told my friends about my husband's behaviour that changed, I got scolded. After that, I keep quiet and do not want to tell other people anymore". (Faridah, 56)

A daughter said,

"I feel stressed because I am the only one who takes care of my parents. When I told my friends, they asked me to be patient, and they scolded me. I have to keep quiet and accept this situation". (Chin, 40)

\section{Subtheme 4b: Self-blame}

Most stroke caregivers blame themselves because they did not closely monitor and making sure that the stroke survivors took their high blood pressure medication.

A wife noted,

"I did not take care of my husband's health. He has hypertension but did not take the medication. Two weeks before he got a stroke, he did not take the medication". (Sarah, 43)

Another wife said,

"When a doctor told me that one could get a stroke if did not take medication for high blood pressure, I feel regretful because I did not ensure my husband took his medication". (Ramlah, 42)

Keep the feeling to oneself and self-blaming are the emotional response based on the reactions from surrounding and viewing that the situation might not happen if stroke caregivers realise about the dire consequences of not following the doctor's instructions (for example in this study, non-compliance for medication for high blood pressure). In summary, the results demonstrated that the caregivers adopt different approaches in coping and managing their family with stroke. 


\section{DISCUSSION}

Stroke caregivers can experience high burden from caring for the stroke survivors, which later can affect their physical and psychological condition negatively ${ }^{16}$. Effective coping strategies may influence caregivers' health outcome such as social functioning, mental and physical health. Stroke caregivers use coping strategies such as acceptance, active coping, positive reframing and planning $^{8}$. The caregiving tasks consume a more substantial amount of energy and time and this will increase caregivers' responsibilities and reduce their leisure time. Stroke caregivers also expressed receiving minimal social support, specifically from their friends and family members that caused them to suppress their emotion and stay quiet. Consistent with previous findings ${ }^{8}$, caregivers perceived of receiving less social support from friends and other members of their social network. In the current study, caregivers took over the role of the household leader. Mostly, the breadwinners of the family who is their husbands are unable to work anymore after getting the stroke. This type of coping strategy involves problem-solving that work the best for the caregivers and stroke survivors. This finding is similar to a study conducted by Murad et al. ${ }^{17}$ as the respondents shows improvements in decreasing their severe level of stress after they learned and adapted coping strategy of problem-solving that reduced their burden enormously. Stroke caregivers who handle their loads effectively have adequate knowledge on self-efficacy and receive good social support ${ }^{18}$. This current study also found out that caregivers blame themselves and claimed to hold the responsibilities of the current problem.

Similarly, findings were reported in the previous study showed that the most usual coping strategies adapted by caregivers were problem-solving, seeking social support, positive distraction and the least coping strategies used were blaming own's fate and distracting negatively ${ }^{5},{ }^{19}$. This is agreed that using passive coping strategies were generally associated with negative outcomes. A community support group can be established to assist stroke caregivers in planning and identify effective coping strategies that will help manage stroke survivors ${ }^{20}$.

There were few limitations identified in this study. The caregivers in this study were recruited from one rehabilitation centre, and the sample size was limited to 18 in number. The research mainly focused on problems met by stroke caregivers in Sarawak. Thus, the results may not be generalised to other settings or caregiver's population of Malaysia. The caregivers were asked to recall their experiences of only stroke survivors, which may be influenced by recall bias. Furthermore, the caregivers were interviewed only once, and they were not followed for the elucidation of differences in experiences.

\section{CONCLUSION}

This study focused on the coping strategies undertaken by stroke caregivers. Caregivers who were engaged with active coping strategies can manage their burdens effectively. Physical and social support from family members, friends, healthcare providers and other professionals were very crucial for stroke caregivers to meet the need of caring demands that will also benefit the stroke survivors. A prospective study to be conducted, using both qualitative and quantitative research approach, to understand changes of caring experience across different stages to get a deeper understanding of care-giving phenomena.

\section{ACKNOWLEDGEMENTS}

We acknowledge the support and help of the Rehabilitation Centre in Kuching, Sarawak. We are also indebted to the caregivers who had kindly participated in this study.

\section{FUNDING}

This study was supported by a grant (Grant no. FRGS/SKK07(01)/974/2013(15) under the Ministry of Higher Education, Malaysia.

\section{COMPETING INTEREST}

The authors declare that they have no competing interests.

\section{REFERENCES}

1. Gaziano TA, Bitton A, Anand S, Abrahams-Gessel S, Murphy A. Growing Epidemic of Coronary Heart Disease in Low- and Middle-Income Countries. Curr Probl Cardiol. 2010;35(2):72-115. doi:10.1016/j.cpcardiol.2009.10.002

2. World Health Organization. Cardiovascular diseases (CVDs). World Health Organization. http://www.who.int/news-room/ fact-sheets/detail/ cardiovascular-diseases-(CVDs). Published in 2017. Accessed July 19, 2018.

3. Fisher M, ladecola $C$, Sacco R. Introduction to the Stroke Compendium. Circ Res. 2017;120(3):437-438. doi:10.1161/CIRCRESAHA.116.31045 3

4. Johnson $W$, Onuma $O$, Owolabi $M$, Sachdev S. Stroke: a global response is needed. Bull World Health Organ. 2016;94(9):634-634A. 
doi:10.2471/BLT.16.181636

5. Kumar R, Kaur S, K R. Burden and coping strategies in caregivers of stroke survivors. J Neurol Neurosci. 2015;6(5):1-5.

doi:10.21767/2171-6625.S10005

6. Lazarus RS, Folkman S. Stress, Appraisal, and Coping. 1st edition. New York, USA: Springer Publishing Company; 1984.

http://www.springerpub.com/

stress-appraisal-and-coping-

9780826141910.html/. Accessed July 19, 2018.

7. Monteiro NM, Balogun SK, Oratile KN. Managing stress: the influence of gender, age and emotion regulation on coping among university students in Botswana. Int J Adolesc Youth. 2014;19(2):153-173.

doi:10.1080/02673843.2014.908784

8. Yu Y, Hu J, Efird JT, McCoy TP. Social support, coping strategies and health-related quality of life among primary caregivers of stroke survivors in China. J Clin Nurs. 2013;22(15-16):2160-2171.

doi:10.1111/jocn.12251

9. National Institute of Neurological Disorders and Stroke. Post-stroke rehabilitation fact sheet. https: //www.ninds.nih.gov/

Disorders/

Patient-Caregiver-Education/Fact-Sh eets/ Post-StrokeRehabilitation-Fact-Sheet. Published in 2018. Accessed July 19, 2018.

10. Lazarus RS. Toward better research on stress and coping. Am Psychol. 2000;55(6):665-673.

11. Dijkstra MTM, Homan AC. Engaging in Rather than Disengaging from Stress: Effective Coping and Perceived Control. Front Psychol. 2016;7. doi:10.3389/fpsyg.2016.01415

12. Thorvaldsen $P$, Kuulasmaa $K$, Rajakangas AM, Rastenyte D, Sarti C, Wilhelmsen L. Stroke trends in the WHO MONICA project. Stroke. 1997;28(3):500-506.

13. Sacco Ralph L, Kasner Scott E, Broderick Joseph P, et al. An Updated Definition of Stroke for the 21st Century.
2013;44(7):2064-2089.

doi:10.1161/STR.0b013e318296aeca

14. Godwin KM, Swank PR, Vaeth P, Ostwald SK. The longitudinal and dyadic effects of mutuality on perceived stress for stroke survivors and their spousal caregivers. Aging Ment Health. 2013;17(4):423-431. doi:10.1080/13607863.2012.756457

15. Braun V, Clarke V. Using thematic analysis in psychology. Qual Res Psychol. 2006;3(2):77-101. doi:10.1191/1478088706qp063oa

16. Bhattacharjee M, Vairale J, Gawali K, Dalal PM. Factors affecting burden on caregivers of stroke survivors: Population-based study in Mumbai (India). Ann Indian Acad Neurol. 2012;15(2):113-119. doi:10.4103/0972-2327.94994

17. Mourad GM, Zaki RA, Ali RA. Improving coping abilities among caregivers of patients with cerebrovascular stroke. J Educ Pract. 2014;5(36):8-20.

www.iiste.org/Journals/ index.php/ JEP/article/download/17466/17725.

18. Van den Heuvel ET, De Witte LP, Schure LM, Sanderman R, Meyboom-de Jong B. Risk factors for burn-out in caregivers of stroke patients, and possibilities for intervention. Clin Rehabil. 2001;15(6):669-677. doi:10.1191/0269215501cr446oa

19. Muthucumarana MW, Samarasinghe K, Elgán C. Caring for stroke survivors: experiences of family caregivers in Sri Lanka - a qualitative study. Top Stroke Rehabil. 2018;25(6):397-402. doi:10.1080/10749357.2018.1481353

20. Visser-Meily A, Post M, van de Port I, Maas C, Forstberg-Wärleby G, Lindeman E. Psychosocial functioning of spouses of patients with stroke from initial inpatient rehabilitation to 3 years poststroke: course and relations with coping strategies. Stroke. 2009;40(4):1399-1404. doi:10.1161/STROKEAHA.108.516682 